\title{
Neck circumference as an indicator of elevated central adiposity in children
}

\author{
Evelyn Valencia-Sosa' ${ }^{1}$ Clío Chávez-Palencia ${ }^{2, *}$, Enrique Romero-Velarde ${ }^{1}$, \\ Alfredo Larrosa-Haro ${ }^{1}$, Edgar Manuel Vásquez-Garibay ${ }^{1}$ and César Octavio Ramos- \\ García $^{2}$ \\ ${ }^{1}$ Instituto de Nutrición Humana, Universidad de Guadalajara, Guadalajara, Jalisco, México: ${ }^{2}$ División de Ciencias \\ de la Salud, Centro Universitario de Tonalá, Av. Nuevo Periférico No. 555, Ejido San José Tatepozco, CP 45425, \\ Tonalá, Jalisco, México
}

Submitted 10 August 2018: Final revision received 30 December 2018: Accepted 23 January 2019: First published online 2 April 2019

\begin{abstract}
Objective: We aimed to study the correlation between neck circumference (NC) and anthropometric adiposity indicators, and to determine cut-off points of NC for both sexes to identify elevated central adiposity in schoolchildren in western Mexico.

Design: Cross-sectional study.

Setting: Rural settings in western México.

Participants: Children from a convenience sample of six schools in Acatlán, Jalisco, Mexico ( $n$ 1802).

Results: NC showed a strong positive correlation with all anthropometric adiposity indicators in both sexes, which were notably higher in boys regardless of age. Noteworthy, waist circumference displayed the highest significant correlation when analysed by both age and sex. As age increased, NC cut-off points to identify elevated central adiposity ranged from $25 \cdot 7$ to $30 \cdot 1 \mathrm{~cm}$ for girls and from 27.5 to $31.7 \mathrm{~cm}$ for boys.

Conclusions: NC could be used as a simple, inexpensive and non-invasive indicator for central obesity assessment in Mexican schoolchildren.
\end{abstract}

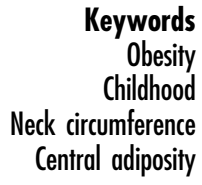

Childhood obesity is a major public health issue. Its incidence in Mexico has increased dramatically over the last few decades. According to preliminary results from the National Survey on Health and Nutrition 2016, the prevalence of overweight and obesity in children aged between 6 and 12 years has exceeded $33 \%{ }^{(1)}$; this places Mexico among the top countries on this topic. Excessive adipose tissue is a risk factor for developing noncommunicable chronic diseases; however, a greater risk has been reported when fat is located in upper body areas $^{(2)}$. Therefore, early identification of overweight and obesity in children is key for health assessment processes to achieve overall well-being in this population ${ }^{(3)}$.

BMI, waist circumference (WC) and waist-to-hip ratio are practical measurements to assess adiposity. The former has been adopted by most health-care practitioners as well as in large-scale epidemiological studies, although it does not identify the amount and distribution of adipose tissue. On the other hand, WC estimates adiposity in the abdominal region and has been associated with dyslipidaemia and $\mathrm{CHD}^{(4,5)}$. However, one of the limitations of this measurement is the lack of a standardized technique. Moreover, ethnic variations and practical obstacles such as clothing removal and other anthropometric variations hinder its international standardization ${ }^{(6)}$. Previously, neck circumference (NC) was proposed as an alternative for adiposity estimation $^{(7)}$. The French scientist Jean Vague ${ }^{(8)}$ was the first researcher who used NC as an indicator of upper body fat. He also proposed the concepts of android and gynoid adiposity to describe local fat deposition. It has been shown that NC not only reflects subcutaneous fat depots near the respiratory tract, but also obesity grade in human populations ${ }^{(2)}$. Noteworthy, in 1995 Sjöström et $a l .{ }^{(9)}$ concluded that upper-body fat estimated by NC measurement could indicate a greater metabolic risk compared with abdominal visceral fat.

Some authors have pointed out that NC might have a supplementary clinical value to other anthropometric measurements in the paediatric population ${ }^{(10)}$. It has been reported in Mexico that acantosis nigricans is associated with $\mathrm{NC}$ in the adult population ${ }^{(11)}$. To the best of our knowledge, there are no studies of Mexican children that 
describe the usefulness of NC along with other anthropometric indicators of adiposity. Therefore, our aims were to assess the correlation between anthropometric adiposity indicators and NC and to establish cut-off points on NC for both sexes at different ages.

\section{Methods}

\section{Selection and description of participants}

Data presented in the current paper are part of a broader project entitled 'Active intervention to improve feeding habits and physical activity in schoolchildren'. The participants belonged to a convenience sample of six schools in Acatlán, Jalisco, Mexico. Only children who were not attending a weight-loss programme or taking any medication, and who were not physically disabled were included. Children with history of chronic disease, neck masses, neck deformity or cervical collar were excluded from the present study.

\section{Technical information}

Prior to the data collection, researchers were trained and standardized in accordance with the Habicht method ${ }^{(12)}$. Height was measured to the nearest $0 \cdot 1 \mathrm{~cm}$ using a portable stadiometer (SECA, Hamburg, Germany) with the participant shoeless and the head held in the Frankfort horizontal plane. Body weight was measured to the nearest $0.05 \mathrm{~kg}$ using a calibrated electronic weighing scale (SECA, Hamburg, Germany) without shoes and heavy clothing. WC was measured to the nearest $0 \cdot 1 \mathrm{~cm}$ with the participant standing, at the end of a normal expiration, using an inelastic tape at the point midway between the lowest rib and the top of the iliac crest. NC was measured at the mid-point of the neck at the level of the thyroid cartilage, with the participant's body held erect, eyes facing forward and normal breathing, using an inelastic tape. To assess body fat composition, we used triceps and subscapular skinfold thickness according to standard techniques ${ }^{(13)}$ and body fat percentage was calculated using Slaughter's equation ${ }^{(14)}$. BMI was calculated by dividing the weight in kilograms by the square of the height in metres.

All measurements were taken twice and the mean was used for the analysis. When the height, weight and circumferences differed by $1 \%$ or more, a third measurement was obtained. This process was also carried out when skinfold thicknesses differed by $5 \%$ or more.

\section{Operational definitions of terms}

Underweight was considered as BMI-for-age $Z$-score (BMIZ) $<-2$, normal weight as BMIZ between -2 and +1 , overweight as BMIZ between +1 and +2 , and obesity as BMIZ $>+2$, in agreement with the $\mathrm{WHO}^{(15)}$. According to previous research ${ }^{(4,16,17)}$, elevated values of WC are related to metabolic disorders in the paediatric population. Importantly, Fernández et $a l .{ }^{(18)}$ have suggested to pay careful attention to children and adolescents with WC values that fall on the 75th up to the 90th percentile according to their ethnic classification and sex. This becomes relevant in the identification of children at risk for various co-morbidities, including CVD, hyperinsulinaemia and type 2 diabetes; consequently, the 75 th percentile was taken to propose cut-off points to identify elevated central adiposity based on WC in our examined population.

\section{Statistics}

Statistical analyses were performed using the statistical software package IBM SPSS Statistics for Windows version 22.0 and MedCalc version 9.4.2.0 (written by Frank Schoonjans, Mariakerke, Belgium). Numerical variables were reported as mean and SD. Comparisons were conducted between groups using Student's $t$ test for independent samples and the $\chi^{2}$ test for qualitative data. Pearson's correlation coefficient was used to measure the strength of the association between $\mathrm{NC}$ and anthropometric adiposity indicators such as WC, BMI, body fat percentage and skinfold thickness. $P<0.05$ was considered statistically significant.

Receiver-operating characteristic curve analysis ${ }^{(19)}$ was used to determine the cut-off values. Elevated central adiposity was defined as a percentile equal to or higher than the 75th percentile in WC, whereas overweight/ obesity was considered as BMIZ $>1$ (for the latter, children with BMIZ $<-2$ were excluded).

\section{Results}

The study sample consisted of 1802 participants (50.3\% girls) aged between 6 and 11 years, who met the criteria described above. Comparison of mean values of age, weight, height, body fat percentage and BMI by sex did not show statistical differences. NC and WC values were significantly higher in boys than in girls. In contrast, skinfold thickness showed significantly higher values in girls (Table 1). Overweight and obesity prevalence in the studied population was 20.5 and $23.0 \%$, respectively. Overweight was present in $18.8 \%$ of boys and $22.2 \%$ of girls, whereas obesity showed a prevalence of 27.2 and $18.7 \%$, respectively $(P<0 \cdot 001)$. According to height-forage $Z$-score, $1.4 \%$ of participants had moderate malnutrition and $0 \cdot 1 \%$ showed severe malnutrition. On the other hand, children with elevated central adiposity (those above the 75 th percentile for WC) accounted for $25 \cdot 2 \%$ in both boys and girls.

Pearson's correlation coefficients between NC and anthropometric adiposity indicators by sex are presented in Table 2. NC showed a strong positive correlation with 
Table 1 Anthropometric measurements and indicators by sex in children aged $6-11$ years ( $n$ 1802) from a convenience sample of six schools in Acatlán, Jalisco, Mexico, November 2015-January 2016

\begin{tabular}{lrrrrrr}
\hline & \multicolumn{2}{c}{ Girls $(n$ 906) } & & \multicolumn{2}{c}{ Boys $(n$ 896) } & \\
\cline { 2 - 3 } Variable & Mean & SD & & Mean & SD & $P$ \\
\hline Age (years) & 8.5 & 1.7 & & 8.6 & 1.7 & 0.756 \\
Weight $(\mathrm{kg})$ & 33.2 & 11.6 & & 34.1 & 12.1 & 0.082 \\
Height $(\mathrm{cm})$ & 133.5 & 12.7 & & 134.0 & 11.7 & 0.369 \\
WC $(\mathrm{cm})$ & 61.8 & 9.6 & & 63.5 & 10.4 & $<0.001$ \\
NC $(\mathrm{cm})$ & 27.4 & 2.6 & & 28.7 & 2.8 & $<0.001$ \\
TSF $(\mathrm{mm})$ & 13.6 & 5.5 & & 12.3 & 5.9 & $<0.001$ \\
SSF $(\mathrm{mm})$ & 11.5 & 6.5 & & 10.6 & 6.9 & $<0.001$ \\
BF\% & 21.6 & 7.7 & & 20.7 & 9.7 & 0.30 \\
BMI $\left(\mathrm{kg} / \mathrm{m}^{2}\right)$ & 18.1 & 3.7 & & 18.5 & 4.1 & 0.21 \\
BMIZ & 0.56 & 1.29 & & 0.82 & 1.58 & $<0.001$ \\
HAZ & 0.16 & 1.06 & & 0.26 & 1.04 & 0.05 \\
\hline
\end{tabular}

WC, waist circumference; NC, neck circumference; TSF, triceps skinfold thickness; SSF, subscapular skinfold thickness; $\mathrm{BF} \%$, body fat percentage; BMIZ, BMI-for-age Z-score; HAZ, height-for-age Z-score.

Table 2 Correlation coefficients between neck circumference and anthropometric adiposity indicators by sex in children aged 6-11 years ( $n$ 1802) from a convenience sample of six schools in Acatlán, Jalisco, Mexico, November 2015-January 2016

\begin{tabular}{lcccccc}
\hline Sex & BF\% & WC & BMI & TSF & SSF & $P$ \\
\hline Girls & 0.79 & 0.91 & 0.86 & 0.78 & 0.75 & $<0.001$ \\
Boys & 0.84 & 0.93 & 0.89 & 0.82 & 0.81 & $<0.001$ \\
\hline
\end{tabular}

NC, neck circumference; BF\%, body fat percentage; WC, waist circumference; TSF, triceps skinfold thickness; SSF, subscapular skinfold thickness.

WC, BMI, body fat percentage and skinfold thickness in both sexes, which were notably higher in boys regardless of age. A noteworthy observation was that WC showed the highest significant correlation when analysed by both age and sex (Table 3).

As shown in Table 4, NC accurately defined elevated WC by sex and age. The area under the curve indicates that for both age and sex, the accuracy levels of $\mathrm{NC}$ for identifying elevated WC were over 0.90 . The NC cut-off points to identify central obesity ranged from $25 \cdot 7$ to $30 \cdot 1$ $\mathrm{cm}$ for girls and from 27.5 to $31.7 \mathrm{~cm}$ for boys between the age of 6 and 11 years. The sensitivity and specificity of this screening method were 83.8-97.0 and 78.4-92.4\%, respectively, for girls and 81.1-100.0 and 83.2-92.5\%, respectively, for boys.

\section{Discussion}

Because of the rapid growth of obesity incidence (tenfold higher over the last 40 years) ${ }^{(20)}$, the development of specific population-based assessment tools for estimating adiposity is becoming an important issue for diagnostic accuracy. Our outcome showed an overall combined overweight/obesity prevalence of $43.5 \%$; this value is higher when compared with the prevalence in Mexico ${ }^{(1)}$ which is $33.2 \%$. Importantly, comparing our results with the population statistics in the region, more specifically those of Jalisco State ${ }^{(21)}$, also appears to be relevant. An example of this is that the occurrence of overweight/ obesity in Jalisco is closer to the data reported herein (39.6 $\%)$. Analysis of overweight/obesity by sex showed that in boys, proportions are similar: $46.0 \%$ in our population and $44.7 \%$ in the state. However, girls showed a higher prevalence: $40.9 v .34 .9 \%$, respectively. In summary, a large proportion of boys showed obesity, whereas girls were more often overweight. This tendency is similar to the national and state statistics.

In our study, we described for the first time in Mexican children the usefulness of NC for assessing elevated central adiposity, evidenced by its high correlation with WC. Many studies conducted in South America, the USA, Europe and a few Middle Eastern countries have evaluated the validity of $\mathrm{NC}^{(7,22-28)}$. These reports have also proposed it as a rapid, easily performed method to identify overweight and obesity. Importantly, one of the most remarkable features of $\mathrm{NC}$ is the almost no need for additional measurements as LaBerge et al. have reported $^{(29)}$.

Remarkably, the correlation coefficients presented herein are consistent with the published reports conducted by Hatipoglu et al. ${ }^{(7)}$ and Nafiu et al. ${ }^{(22)}$. However, our outcome showed higher correlations between NC and both WC $(r=0.91)$ and BMI $(r=0.86)$ than those of these studies. This might be explained by the selection criteria and the nature of the population itself. On the one hand, our evaluated population was obtained from six schools in the south-western state of Jalisco. Unlike the methodology applied by those studies, we did not use case-control design, nor did we recruit children from clinical facilities. Indeed, our data are widely supported by the size and heterogeneity of the population studied.

We found high correlations in anthropometric adiposity indicators by sex and age. In girls, the correlations ranged from 0.72 to 0.90 , while in boys from 0.79 to 0.93 . In this regard, WC and BMI showed the highest correlations. Although other authors have reported similar tendencies, correlations in their studies have been lower. For instance, Coutinho et al. ${ }^{(24)}$ reported correlations ranging from 0.64 to 0.86 in girls and from 0.44 to 0.86 in boys. Of note, correlations in boys were markedly lower compared with girls. On the other hand, Lou et $a l^{(30)}$ reported lower correlations for WC in girls ranging from 0.56 to 0.74 . This finding might be due to the ethnic differences in the studied populations and the different overweight and obesity prevalence rates $(40.9 \%$ in our study $v .27 .4 \%$ in Lou et al.'s study). This suggests that overweight/obesity prevalence in a given population might play an important role in the analysis of correlations.

A plausible explanation for the high correlation we observed between NC and other anthropometric adiposity 
Table 3 Correlation coefficients between neck circumference and anthropometric adiposity indicators by sex and age in children aged 6-11 years $(n$ 1802) from a convenience sample of six schools in Acatlán, Jalisco, Mexico, November 2015-January 2016

\begin{tabular}{|c|c|c|c|c|c|c|c|c|}
\hline Sex & $\begin{array}{c}\text { Age } \\
\text { (years) }\end{array}$ & $n$ & BF\% & WC & BMI & TSF & SSF & $P$ \\
\hline \multirow[t]{6}{*}{ Girls } & 6 & 149 & 0.74 & 0.86 & 0.82 & 0.74 & 0.73 & $<0.001$ \\
\hline & 7 & 150 & 0.74 & 0.86 & 0.81 & 0.71 & 0.70 & $<0.001$ \\
\hline & 8 & 147 & 0.84 & 0.89 & 0.89 & 0.83 & 0.83 & $<0.001$ \\
\hline & 9 & 171 & 0.78 & 0.90 & 0.89 & 0.76 & 0.76 & $<0.001$ \\
\hline & 10 & 158 & 0.77 & 0.90 & 0.88 & 0.75 & 0.75 & $<0.001$ \\
\hline & 11 & 130 & 0.77 & 0.82 & 0.80 & 0.72 & 0.75 & $<0.001$ \\
\hline \multirow[t]{6}{*}{ Boys } & 6 & 143 & 0.85 & 0.89 & 0.89 & 0.84 & 0.81 & $<0.001$ \\
\hline & 7 & 139 & 0.82 & 0.87 & 0.86 & 0.80 & 0.80 & $<0.001$ \\
\hline & 8 & 141 & 0.82 & 0.93 & 0.89 & 0.80 & 0.79 & $<0.001$ \\
\hline & 9 & 170 & 0.85 & 0.91 & 0.88 & 0.83 & 0.83 & $<0.001$ \\
\hline & 10 & 160 & 0.87 & 0.91 & 0.90 & 0.86 & 0.83 & $<0.001$ \\
\hline & 11 & 143 & 0.83 & 0.92 & 0.92 & 0.83 & 0.81 & $<0.001$ \\
\hline
\end{tabular}

$\mathrm{NC}$, neck circumference; $\mathrm{BF} \%$, body fat percentage; WC, waist circumference; TSF, triceps skinfold thickness; SSF, subscapular skinfold thickness.

indicators might be the fact that this body region exerts a high lipolytic activity. According to several studies, serum NEFA are mostly released from the upper body region, and even in a greater manner than from visceral fat ${ }^{(31,32)}$. Other reports have shown that NC is a useful tool for identifying upper-body adiposity ${ }^{(33-35)}$.

Previous research indicates that up to a certain point, neck adipose tissue should be regarded as an ectopic fat depot. This concept has its origin in the following hypothesis: when an excess of TAG cannot further expand into metabolically favourable depots, they infiltrate into tissues that are able to store only a small amount of fat. In fact, ectopic fat is considered to have properties of dysfunctional adipose tissue and it is closely related to metabolic alterations ${ }^{(36)}$.

Several authors have proposed NC as a metabolic syndrome indicator for pre-school and school children, as well as adolescents ${ }^{(6,23,37-43)}$. NC has been related to nonalcoholic fatty liver and cut-off points for its identification have been proposed ${ }^{(44)}$. Figueroa-Sosa et al. ${ }^{(45)}$ recently highlighted the importance of having an easy-to-apply tool such as NC, mainly for use in marginalized communities where often there is no access to anthropometric equipment such as a scale or stadiometer.

One of the aims of the present study was to propose NC cut-off points based on WC to identify elevated central adiposity. In this regard, the International Diabetes Federation states that $\mathrm{WC} \geq 90$ th percentile is an indicator for metabolic risk in children ${ }^{(46)}$. However, as stated in the 'Methods' section, we decided to use the 75 th percentile as a cut-off point to identify children with elevated central adiposity. The reason for this is that Fernández et al. ${ }^{(18)}$ found on the 75th and 90th percentiles that MexicanAmerican girls evidenced the fastest overall WC increase of all girls. Besides, at any of the percentiles considered, Mexican-American people showed the highest overall WC and the fastest overall rate of $\mathrm{WC}$ increase with age.
Therefore, due the high prevalence of overweight and obesity in Mexico, we considered that early identification of population at risk is highly important.

On the other hand, the previously mentioned reports have addressed the validity of NC by creating cut-off points based on the Centers for Disease Control and Prevention growth charts for BMI. Nevertheless, Hassan et $a l .{ }^{(47)}$ pointed out the importance of cautiousness when using NC as a screening tool. In the first place, a gold standard would be optimal for this determination, and in the second place, BMI by itself is not a good proxy for regional adiposity. In this regard, we propose, for the first time, using NC cut-off values based on WC. We found that NC cut-off points for elevated central adiposity could be proposed as follows: for girls, $25 \cdot 7-30 \cdot 1 \mathrm{~cm}$ in the age range of 6-11 years old, while for boys, $27.5-31.7 \mathrm{~cm}$ on the age range 6-11 years old. In fact, values of area under the curve based on WC were slightly higher than those based on BMI, as reported in other studies where similar cut-off points were proposed ${ }^{(26,30)}$. Importantly, due to the high prevalence of overweight and obesity in the studied population, the cut-off points could only be useful in geographical regions with similar prevalence. As mentioned before, Jalisco State and our study showed similar statistics.

This evidence supports the accuracy of NC for the prediction of elevated central adiposity. Although WC is not a gold standard, it has been proved to be an accurate indicator of central adiposity, which in turn is highly associated with metabolic risk regardless of age ${ }^{(4,5)}$. The authors of the present paper want to emphasize that despite the difficulties in measuring WC, when applied optimally, it provides valuable information on central adiposity. On the other hand, NC presents certain technical advantages compared with WC. First, it does not require clothing removal, which makes it more convenient in cold weather and feasible for some cultures. Second, it is not altered by respiratory movements or postprandial abdominal distension, diminishing the need for additional confirmatory measurements.

One report found that it is feasible to effectively obtain accurate self-measurements using a flexible, inelastic, paper tape measure self-assembled from a PDF file downloaded from the Internet for large-scale consumer surveys where participants could not easily visit anthropometric labs for measurement by trained technicians. The authors of that report demonstrated a simple, inexpensive method for teaching novice mothers of young children to obtain their own body circumferences in which $\mathrm{NC}$ was measured, resulting in accurate and reliable data. They concluded that collecting self-measured and self-reported circumference data in future studies might be a useful approach for body composition research ${ }^{(48)}$. These results might suggest that NC measurement could be performed by parents or teachers given that there is no need for previous specialized training for this anthropometric 
variable, which in turn facilitates the identification of elevated central adiposity in children both at home and in school.

We acknowledge the worldwide importance and acceptance of both BMI and WC as practical tools. However, our report attempts to highlight the supplementary validity of $\mathrm{NC}$ as a time-saving tool in large epidemiological studies as well as in daily clinical practice for the identification of increased adiposity. We also acknowledge that to achieve practical acceptance, additional studies should be conducted in other strategic regions given the admixture background of its population; consequently, our proposed cut-off points provide high accuracy but are limited to the population in the studied region. Finally, further studies on NC including metabolic risk parameters could strengthen the evidence of its usefulness.

\section{Conclusion}

NC could be used as a simple, inexpensive and noninvasive indicator for central obesity assessment in Mexican schoolchildren.

\section{Acknowledgements}

Acknowledgements: The authors acknowledge the financial funding from the Tresmontes Lucchetti Company and the support of the National Institute of Public Health. The authors thank Roberto Rodriguez-Echevarria, $\mathrm{PhD}$, for manuscript review. Financial support: The broader project where this work belongs was funded by the Tresmontes Lucchetti Company, Universidad de Guadalajara and the Instituto Tecnológico de Estudios Superiores de Occidente. These funding agencies had no role in the design, analysis or writing of this article. Conflict of interest: None. Authorship: E.V.-S. and C.C.-P. conceptualized and designed the study and drafted the initial manuscript. A.L.-H., E.R.-V., E.M.V.-G. and E.V.-S. carried out the initial analyses and reviewed and revised the manuscript. C.O.R.-G., E.V.-S. and C.C.-P. designed the data collection instruments, coordinated and supervised the data collection, and critically reviewed the manuscript. All authors approved the final manuscript as submitted and agreed to be accountable for all aspects of the work. Ethics of human subject participation: This study was conducted according to the guidelines of the Declaration of Helsinki. All procedures involving human subjects were approved by the Comité de Ética en Investigación del Centro Universitario de Tonalá (003-2016). Verbal informed consent was obtained and formally recorded from all schoolchildren and their tutors. Written informed consent was obtained from all school directors. 


\section{References}

1. Shamah-Levi T, Cuevas-Nasu L, Dommarco-Rivera J et al. (2016) Encuesta Nacional de Salud y Nutrición de Medio Camino 2016. México, DF: Secretaría de Salud.

2. Lee JJ, Pedley A, Therkelsen KE et al. (2017) Upper body subcutaneous fat is associated with cardiometabolic risk factors. Am J Med 130, 958.e1-966.e1.

3. Kim Y, Lee J-M, Laurson K et al. (2014) Accuracy of neck circumference in classifying overweight and obese US children. ISRN Obes 2014, 781841.

4. Maffeis C, Pietrobelli A, Grezzani A et al. (2001) Waist circumference and cardiovascular risk factors in prepubertal children. Obes Res 9, 179-187.

5. Moschonis G, Karatzi K, Polychronopoulou MC et al. (2016) Waist circumference, trunk and visceral fat cutoff values for detecting hyperinsulinemia and insulin resistance in children: the Healthy Growth Study. Eur J Nutr 55, 2331-2334.

6. Da Silva CC, Zambon MP, Vasques AC et al. (2014) Neck circumference as a new anthropometric indicator for prediction of insulin resistance and components of metabolic syndrome in adolescents: Brazilian Metabolic Syndrome Study. Rev Paul Pediatr 32, 221-229.

7. Hatipoglu N, Mazicioglu MM, Kurtoglu S et al. (2010) Neck circumference: an additional tool of screening overweight and obesity in childhood. Eur J Pediatr 169, 733-739.

8. Vague J (1956) The degree of masculine differentiation of obesities: a factor determining predisposition to diabetes, atherosclerosis, gout, and uric calculous disease. Am J Clin Nutr 4, 20-34.

9. Sjöström CD, Håkangård AC, Lissner L et al. (1995) Body compartment and subcutaneous adipose tissue distribution - risk factor patterns in obese subjects. Obes Res 3, 9-22.

10. Yang L, Samarasinghe YP, Kane P et al. (2010) Visceral adiposity is closely correlated with neck circumference and represents a significant indicator of insulin resistance in WHO grade III obesity. Clin Endocrinol (Oxf) 73, 197-200.

11. Hernández-Escalante VM, Cabrera-Araujo Z \& Euán-Braga G (2013) Relación de la circunferencia del cuello con la glucemia y la acantosis nigricans. Rev Endocrinol Nutr 21, 159-163.

12. Habicht JP (1974) Standardization of quantitative epidemiological methods in the field. Bol Oficina Sanit Panam 76, 375-384

13. Stewart A, Marfell-Jones M, Olds $\mathrm{T}$ et al. (2011) International Standards for Anthropometric Assessment. Lower Hutt, New Zealand: International Society for the Advancement of Kinanthropometry.

14. Slaughter AMH, Lohman TG, Boileau RA et al. (2013) Skinfold equations for estimation of body fatness in children and youth. Hum Biol 60, 709-723.

15. De Onis M, Onyango AW, Borghi E et al. (2007) Development of a WHO growth reference for school-aged children and adolescents. Bull World Health Organ 85, 660-667.

16. Okosun IS, Chandra KM, Choi S et al. (2001) Hypertension and type 2 diabetes comorbidity in adults in the United States: risk of overall and regional adiposity. Obes Res $\mathbf{9}$, $1-9$.

17. Goran MI \& Gower BA (1998) Abdominal obesity and cardiovascular risk in children. Coron Artery Dis 9, 483-487.

18. Fernández JR, Redden DT, Pietrobelli A et al. (2004) Waist circumference percentiles in nationally representative samples of African-American, European-American, and MexicanAmerican children and adolescents. J Pediatr 145, 439-444.

19. Van der Schouw YT, Verbeek ALM \& Ruijs JHJ (1992) ROC curves for the initial assessment of new diagnostic tests. Fam Pract 9, 506-511.

20. Di Cesare M, Bentham J, Stevens GA et al. (2016) Trends in adult body-mass index in 200 countries from 1975 to 2014: a pooled analysis of 1698 population-based measurement studies with 19.2 million participants. Lancet 387, 1377-1396.

21. Instituto Nacional de Salud Pública (2013) Encuesta Nacional de Salud y Nutrición 2012. Resultados por entidad federativa, Jalisco. Cuernavaca, México: Instituto Nacional de Salud Pública.

22. Nafiu OO, Burke C, Lee J et al. (2010) Neck circumference as a screening measure for identifying children with high body mass index. Pediatrics 126, e306-e310.

23. Androutsos O, Grammatikaki E, Moschonis G et al. (2012) Neck circumference: a useful screening tool of cardiovascular risk in children. Pediatr Obes 7, 187-195.

24. Coutinho CA, Longui CA, Monte O et al. (2014) Measurement of neck circumference and its correlation with body composition in a sample of students in Sao Paulo, Brazil. Horm Res Paediatr 82, 179-186.

25. Hassan NE, Atef A, El Masry SA et al. (2015) Is neck circumference an indicator for metabolic complication of childhood obesity? Open Access Maced J Med Sci 3, 26-31.

26. Taheri M, Kajbaf TZ, Taheri MR et al. (2016) Neck circumference as a useful marker for screening overweight and obesity in children and adolescents. Oman Med J 31, $170-175$.

27. Kondolot M, Horoz D, Poyrazoğlu S et al. (2017) Neck circumference to assess obesity in preschool children. J Clin Res Pediatr Endocrinol 9, 17-23.

28. Kelishadi R, Djalalinia S, Motlagh ME et al. (2016) Association of neck circumference with general and abdominal obesity in children and adolescents: the weight disorders survey of the CASPIAN-IV study. BMJ Open 6, e011794.

29. LaBerge RC, Vaccani JP, Gow RM et al. (2009) Inter- and intra-rater reliability of neck circumference measurements in children. Pediatr Pulmonol 44, 64-69.

30. Lou D-H, Yin F-Z, Wang R et al. (2012) Neck circumference is an accurate and simple index for evaluating overweight and obesity in Han children. Ann Hum Biol 39, $161-165$.

31. Guo Z, Hensrud DD, Johnson CM et al. (1999) Regional postprandial fatty acid metabolism in different obesity phenotypes. Diabetes 48, 1586-1592.

32. Torriani M, Gill CM, Daley S et al. (2014) Compartmental neck fat accumulation and its relation to cardiovascular risk and metabolic syndrome. Am J Clin Nutr 100, 1244-1251.

33. Stabe C, Vasques ACJ, Lima MMO et al. (2013) Neck circumference as a simple tool for identifying the metabolic syndrome and insulin resistance: results from the Brazilian Metabolic Syndrome Study. Clin Endocrinol (Oxf) 78, 874-881.

34. Iraj B, Mirpourian M, Shariatifar B et al. (2014) Association of neck circumference as an indicator of upper body obesity with cardio-metabolic risk factors among first degree relatives of diabetes patients. Adv Biomed Res 3, 237.

35. Lee JJ, Pedley A, Therkelsen KE et al. (2017) Upper body subcutaneous fat is associated with cardiometabolic risk factors. Am J Med 130, 958-966.

36. Mittendorfer B (2011) Origins of metabolic complications in obesity: adipose tissue and free fatty acid trafficking. Curr Opin Clin Nutr Metab Care 14, 535-541.

37. Kelishadi R, Heidari-Beni M, Qorbani M et al. (2017) Association between neck and wrist circumferences and cardiometabolic risk in children and adolescents: the CASPIANV study. Nutrition 44, 32-38.

38. Pereira DCR, Araújo MFM, Freitas RWJF et al. (2014) Neck circumference as a potential marker of metabolic syndrome among college students. Rev Lat Am Enfermagem 22, 973-979.

39. Formisano A, Bammann K, Fraterman A et al. (2016) Efficacy of neck circumference to identify metabolic syndrome in 3-10 year-old European children: results from IDEFICS study. Nutr Metab Cardiovasc Dis 26, 510-516. 
40. Castro-Piñero J, Delgado-Alfonso A, Gracia-Marco L et al. (2017) Neck circumference and clustered cardiovascular risk factors in children and adolescents: crosssectional study. BMJ Open 7, e016048.

41. Gomez-Arbelaez D, Camacho PA, Cohen DD et al. (2016) Neck circumference as a predictor of metabolic syndrome, insulin resistance and low-grade systemic inflammation in children: the ACFIES study. BMC Pediatr 16, 31.

42. Gonçalves VSS, Faria ER, Franceschini SCC et al. (2014) Neck circumference as predictor of excess body fat and cardiovascular risk factors in adolescents. Rev Nutr $\mathbf{2 7}$, 161-171.

43. Kurtoglu S, Hatipoglu N, Mazicioglu MM et al. (2012) Neck circumference as a novel parameter to determine metabolic risk factors in obese children. Eur J Clin Invest 42, 623-630.
44. Hatipoğlu N, Doğan S, Mazıcıŏlu MM et al. (2016) Relationship between neck circumference and non-alcoholic fatty liver disease in childhood obesity. J Clin Res Pediatr Endocrinol 8, 32-39.

45. Figueroa-Sosa EC, García-Rojas E, Oropeza-Priego S et al. (2017) La circunferencia del cuello y su relación con el sobrepeso en infantes. Rev Sanid Milit Mex 71, 248-257.

46. Alberti SG, Zimmet P, Kaufman F et al. (2007) The metabolic syndrome in children and adolescents - an IDF consensus report. Pediatr Diabetes 8, 299-306.

47. Hassan NE, Atef A, El-Masry SA et al. (2015) Neck circumference as a predictor of adiposity among healthy and obese children. Maced J Med Sci 3, 558-562.

48. Barrios P, Martin-Biggers J, Quick V et al. (2016) Reliability and criterion validity of self-measured waist, hip, and neck circumferences. BMC Med Res Methodol 16, 49. 